\title{
Understanding the traditional customary law of the Yi people via ethnographic film - collaborative ethnographic film making process
}

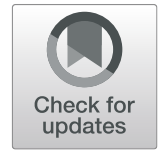

\author{
Tao Pang (D)
}

Received: 6 May 2020 / Accepted: 7 June 2020 / Published online: 19 June 2020

(C) The Author(s). 2020 Open Access This article is licensed under a Creative Commons Attribution 4.0 International License, which permits use, sharing, adaptation, distribution and reproduction in any medium or format, as long as you give appropriate credit to the original author(s) and the source, provide a link to the Creative Commons licence, and indicate if changes were made. The images or other third party material in this article are included in the article's Creative Commons licence, unless indicated otherwise in a credit line to the material. If material is not included in the article's Creative Commons licence and your intended use is not permitted by statutory regulation or exceeds the permitted use, you will need to obtain permission directly from the copyright holder. To view a copy of this licence, visit http://creativecommons.org/licenses/by/4.0/.

\begin{abstract}
This paper will take the film The Rules from Ancestors as the basis to discuss the "writing" process of ethnographic film, addressing how a contemporary visual ethnography can be realized through the presentation of a film on ethnic culture.

The Rules from Ancestors is an anthropological film about the Traditional Customary Law of the Yi people in China, produced by the author of this paper in 2006. As an integrated anthropological film, its theoretical basis is the "holism" and "legal pluralism" of legal anthropology, and its stories are narrated through objective observation and interactive collaboration. The author attempted to construct an "intermediary context" within the film's narrative structure. The aim was to establish an experimental visual ethnographic expression that progresses from "complicity" to "sharing", to replace the traditional ethnographic mode of expression, localized fieldwork. In so doing, I hoped to explore the possibilities of collaborative knowledge production between the photographer, the subject, and the audience, as well as a non-unidirectional methodology for the flow and transfer of knowledge.

Through the exploration described above, this paper attempts to respond to the ongoing debate on the relationship between visual anthropology and written anthropology. Is anthropological film a "self-contained system reaching the same goal with different methods", or simply an "auxiliary tool" of written
\end{abstract}

T. Pang $(\bowtie)$

Beijing, China

e-mail: pangtao@cass.org.cn 
anthropology? Based on an ethnographic introspection on anthropological filmmaking practices, this paper will provide explicit support to the former standpoint, as well as a discussion on methodology.

Keywords Ethnographic film $\cdot$ Customary law $\cdot$ Share $\cdot$ Complicity

\section{Introduction}

As one of many customary laws practiced by China's ethnic minorities, the Traditional Customary Law of the Yi people in Liangshan Prefecture is still operational today and generates a relatively sound folk society control system. To this day, the law has played an important role in the Yi people's daily lives, and has been attracting the attention of numerous scholars since China's republican period (1911-1949). Customary laws (or folk laws) are usually discussed in the context of legal science, sociology, ethnology, and anthropology, producing many enlightening research achievements. However, when using only abstract written work and dull theoretical discussions, it is often difficult to attract the understanding and attention of the outside world towards the living culture of the Yi people's Traditional Customary Law. My project collaborator, Mr. Jingyuan Chen, once studied the customary laws of ethnic groups such as the Monba and Lhoba. We have always been attracted to the idea of using visual methods to study the customary laws of ethnic minorities. Then, in 2006, we got the opportunity to run an anthropological film project on the Traditional Customary Law of the Yi people. Previously, there was already plenty of textual ethnographic studies on the topic, yet there had been no attempts to describe it in the form of visual ethnography. We were concerned about whether it would be possible for film, in its representational nature, to sufficiently demonstrate and analyze such an abstract and complex cultural system. In reality, research on customary laws is usually based on case studies. Compared with written text, the main advantage of film lies in the representation of events and cases. We intend to document a number of Customary Law cases and their cultural backgrounds in order to reveal the operational process, status, and environment of the Traditional Customary Law of the Yi people.

Generally, when researching and describing a cultural event by means of ethnographic film, first of all we face two choices. One pertains to disciplinary concerns, namely, the film's so-called academic content. The other is in selecting the forms of visual expression, that is, the strategies and methods of film narration. Unlike footage shot during fieldwork, a finished anthropological film should include both academic content and expressive forms. Unlike modern legal science, legal anthropology is a "study of law taken from perspectives such as social anthropology, cultural anthropology, and ethnography (Yuasa et al., 2001; Chiba, 1997). It is based on anthropological viewpoints, lived experiences and feelings, and cross-cultural comparison, aiming to criticize the legal concepts and research methods of traditional jurisprudence." Anthropology and jurisprudence have "mutually infiltrated" upon the boundaries of their respective disciplines to form the "emerging" interdisciplinary field "legal anthropology". 
This project intends to observe the traditional customs and culture of the Yi people using the methodology of legal anthropology. Since the late 1960s, the legal anthropology discipline, with the UK and US as its center, has shifted its mode of study from researching primitive and tribal laws, to researching disputes. This represents a move away from mainly researching legal systems that are dominated by formalized rules and adjudication (primarily substantive law), turning instead towards the study of disputes and their handling process. (Zhang Guanzi (张冠梓), 2003) E. Adamson Hoebel writes in his book, The Law of Primitive Man - A Study in Comparative Legal Dynamics, that in the study of legal anthropology, there are three main research methods in use. The first is to summarize rules among the local people and obtain theoretical clues; the second is to observe the local people's behavior, looking for descriptive clues to discuss the modes on which actual behavior is based; the third method is to use case studies of events such as disputes and conflicts to identify their causes and solutions. In addition, one could apply the third method to investigate the inner motivations behind a problem and the results of the dispute's settlement, if possible. (Hebel, 1993) The third method is the "method for analyzing dispute cases", which is distinct from the first two. The first two methods are based on ideal norms, and search for various legal facts that are consistent with these norms in real life. Meanwhile, the method of analyzing dispute cases starts from the actual disputes themselves, and ultimately summarizes the universal meanings of the research subjects into a general the code of conduct. Therefore, based on anthropological fieldwork, this film "aims to reflect and analyze dispute cases so as to summarize the universal meanings in the form of an ethnographic film".

However, for many anthropologists who present their research results through written papers, filmmaking is indeed a complex and difficult media to master. Therefore, compared with written anthropological pieces, academic thoughts presented through visual forms are often considered to be restricted by the expressive limits of their visual media, making them difficult to properly interpret. This bring us to the inherent debate about Visual Anthropology, "Whether the film is only suitable for the description of real events, or for expressing subjective feelings or emotions? And what does film have by way of a discriminating ability?"

"Visual anthropology has positive connotations for people to reflect upon anthropology, yet it is bound to be marginalized in the discipline due to its own restrictions.” (Hu Hongbao (胡鸿保) and Yang Yuzhen (杨玉珍), 2006) Most of us do not have the opportunity to be trained in visual language as we are with oral or written language, from birth all the way to university. In other words, specific training is needed to be able to tell a narrative visually (as well as to read narratives that are told through images). Therefore, we should not be bound by hurried conclusions drawn by scholars who have not even mastered the basics of filmic expression. An example to support this is that, although only a hundred or so years old, the progress made by commercial film and visual products within the public realm is undeniable; they can express all aspects of emotion, aesthetics, illusion, thought, and consciousness, in an ongoing process of varied trial and experimentation. Therefore, we must reflect on whether film's contentious position within the academic field is due to the scholars ourselves? Just as David MacDougall (2001:129) said, "The many coarse and 
ambiguous ethnographic films that have been made only serve to feed claims that film is incapable of discursive analysis." Of course, we hope to produce an anthropological film that can meet our high expectations. We hope that, through detailed observation and documentation, we can allow people to more easily share and experience the cultural events involved in Yi Customary Law, helping to build people's knowledge and understanding of the Yi people. Yet, the difficulty in fulfilling this goal lies in finding the suitable narrative filmmaking techniques to allow the intangible cultural meanings concealed within $\mathrm{Yi}$ cultural events to be transmitted and understood between the observer, the observed, and the audience.

This paper will use the film The Rules from Ancestors as the basis for a discussion on the "writing" process of ethnographic filmmaking, looking at how the presentation of localized ethnographic film can provide reflections on contemporary ethnographic film practices. The Rules from Ancestors - Sigei (death as a protest), and Jiewei, Customary Law of the Yi People is an ethnographic film I shot in Guli District, Zhaojue County, Liangshan Yi Autonomous Prefecture, Sichuan Province between 2006 and 2008. In the process of filmmaking, we reflected on the traditional observational ethnographic film and a produced new experimental method for ethnographic filmmaking. In practice, the shooting process produced two effects. The first was that, while working with local informants to make the film, we replaced the traditional approach of "emic" observation with a method involving our informants as consultants and collaborators. We found that both sides were inspired to reflect on their own knowledge, allowing us to remove obscurity from the concepts we often take for granted. In this way, we have found a method and process through which our film-making practice can reveal the holistic cultural relations at play among our informants. The second effect is that the shooting of this film promoted "cultural self-awareness" in both the local government and the folk society. Afterwards, Jiewei, a customary law as part of of the Yi people's informal legal system, and Degu, the role of the mediator, have since been incorporated into the local "folk mediation" system as a local supplement to the formal legal system in the ethnic areas. The application was approved for Degu to be named as the inheritor of "intangible culture" by the Cultural Department of the local government, and the mediation custom was listed as part of China's official intangible cultural heritage in 2008 .

\section{Discussion}

In October 2006, we arrived in Guli District, Zhaojue County with our camera equipment. We found that collecting footage is much more difficult than written material. Between all the elements of the Customary Law of the Yi people, including dispute cases, Degu (the mediator), and Jiewei (the customary laws themselves), the dispute cases is the hardest element to record live. In fact, we went to Liangshan Prefecture twice between 2006 and 2007, and all that we obtained is basically written material. We only shot footage of the interviews with Degu and scenery shots of the local environment. Although the local collaborator Ebi Jiefang was working with us, we could only "hear" or learn about cases after they 
happened by visiting the people involved, while the minimum requirement for any filming observation and recording is being present. To capture such dynamic events, we not only needed adequate preparation in advance, but also a degree of luck. Given that our previous filmmaking paid more attention to static and regular cultural events, such as religious activities, rituals, and surveys of small communities, we experienced unprecedented difficulties in shooting the film for this project. It took tremendous time, energy, and financial resources to support us until we were finally lucky enough to observe the dispute settlement process according to customary law. We went to Guli District, Zhaojue County four times, and finally managed to shoot some cases involving mediation by customary law, including the "Sigei Case" that we were very interested in. It should be noted that the previous surveys were very important as they allowed us to accumulate local knowledge, establish good contacts among the local people, and integrate into the local environment. Without this groundwork, no matter how lucky we were, we may never have had the same opportunities to shoot live cases.

The customary law of the Yi people in Liangshan: Jiewei and Degu

"Customary law" is an imported concept to China, first proposed in Western academic circles. It was not until the 1950s that this concept was introduced and first applied in China, in a nationwide social historical survey of ethnic minorities. ${ }^{1}$ Traditional Yi society in Liangshan use the word Jiewei to refer to their customary law system. Jiewei translates to "rules" or "systems" in English. The legal culture that was formed throughout the Yi people's history includes elements such as customary law, religion, and social customs. In ancient times, Yi society had no $\mathrm{Ya}$ men (衙门, a government law enforcement office in feudal China), courts or arbitral tribunals, but only a strict social hierarchy. In this hierarchy, the ruling class consisted of the Zimo (the chieftain) and Nuohuo (Black Yi people), responsible for governing the Qunиo (White Yi people), Ajia (slaves), and Xiaxi (slaves, the lowest class in the $\mathrm{Yi}$ society). The whole society operated according to the traditional customary law to settle conflicts and keep clear the relations of all social strata. Criminal cases and civil disputes were mediated and judged by the Degu of the Yi region in accordance with Jiewei. Although there is no written record of Jiewei throughout history, it is supported by the public and bears legal effect. Jiewei has been passed from generation to generation and is widely acknowledged by the Yi people as the mandatory set of rules to follow in settling disputes, which no one is above. It is the law with the highest authority in Yi society and is strictly and comprehensively enforced.

$D e g u$ is a transliterated word from the Yi language. It generally has two meanings. First, it refers to a person, who is the wealthy, prominent and influential figure with sublime authority in his own lineage and even other lineages. They must

\footnotetext{
${ }^{1}$ See Zhou Yong (周勇). July 1998. Methods and Problems of Legal Ethnography - Review on the Records of the Inherent Law of Ethnic Minorities in the Social and Historical Survey of Ethnic Minorities in China from 1956 to 1964 《法律民族志的方法和问题——1956-1964年中国少数民族社 会历史调查对少数民族固有法的记录评述》, Anthropology and Ethnic Groups of Southwest China《人 类学与西南民族》, Yunnan University Press, Issue 1, p. 321.
} 
be eloquent, cultivated, well-informed, impartial, willing to help others, and familiar with Yi Customary Law and its cases so that they are able to settle major disputes in accordance with this law. Second, Degu refers to the folk activities of the Yi people at a certain scale, when the Yi people gather together to negotiate or handle community affairs. The leaders of such activities are called Mo. Therefore, a Degu is also called Mo when they are settling a particular dispute. There is a saying that goes in the Yi society, "In Han-inhabited regions, the officials are the authority, in Yi-inhabited regions, the Degus are the authority, and in Tibetaninhabited regions, the Lamas are the authority." If Jiewei is the unwritten law used to settle various disputes and affairs between individuals or lineages in Liangshan, the Degu is both the arbitrator and executor of this unwritten law. We found that when settling a case, a Degu would analyze the case at hand in reference to legal provisions that they had memorized. Then, they would pass a judgment according to the degree of crime committed by the offender. The Degus are regarded as the secular authority in Liangshan's Yi society, yet the confirmation of their authority is dependent on their ability to follow, master, and apply the traditional customary law.

Returning to our filmmaking, when planning the film's content, we thought about what form of expression would best demonstrate the elements behind the local customary law, such as dispute cases, Degu behaviors, rules within the customary law, and its cultural background. After a period of surveying, we decided to adopt two development clues in the film: one event and one character. The event clue shows the interaction between the parties involved in an incident by shooting the settlement process of several dispute cases. By following and shooting a certain Degu, our character clue observes and records the Degu's behavior as he uses customary law to settle disputes. We decided it would be best if it was the same Degu connecting all the events in the film.

The anthropological film can be distinguished from a general documentary by its observational methods, or by taking a perspective based on anthropological ideas. Although we approve of the diversified direction in which anthropological film is developing, when it comes to our own project, which is defined as an "ethnographic film about the Customary Law of the Yi People", we need a certain theoretical foundation. Thus, in our investigation of folk customary law, our theoretical basis was derived from legal anthropology's concepts of "holism" and "legal pluralism".

The holistic view of anthropology holds that law should be regarded as a part of society as a whole and an element of culture. In the tradition of anthropological research, anthropologists usually observe, study, and comprehend cultural phenomena as entities in and of themselves that are interconnected and interactive. As an aspect of human culture, the research of law cannot be separated from other social phenomena. We not only need to pay attention to legal phenomena themselves, but also the role of law in social operation, people's daily life, and cultural maintenance. Legal pluralism is an important theory and method that came into being in recent years through research on the sociology of law and legal anthropology. It is generally believed that the co-existence between state laws, non-governmental laws, or customary laws constitutes the foundation of legal pluralism. For instance, 
Pospisil (1971) believes in the multiplicity of legal systems since there are different social groups in a society and a corresponding legal system, the laws within which comprise a hierarchical structure.(Pospisil, 1971:40 91) Masaji Chiba (1997) posits that laws have a ternary structure, including laws stipulated or approved by the state (formal laws); laws established by special groups based on public will, which hold authority and play a certain role, yet are not recognized by the state (informal laws); and the fundamental principles that necessitate the establishment and implementation of these laws (premise of law). (Yuasa et al., 2001) The perspective of legal pluralism allows for a broader scope of research on customary laws, by foregrounding the object of study against the backdrop of diverse coexisting legal systems. This perspective concerns itself with the social status, intimacy, cultural distance, interdependency, and the degree of respect paid towards the parties involved in the case and third parties. It provides more methods and ideas for us to study customary laws.

The Customary Law of the Yi people in Liangshan covers a wide range and contains complicated rules. During the survey of ethnic minority social histories carried out in the 1950s in China, a large number of customary legal clauses were collected and organized from Bapu District of Meigu County, Zhuhe Township, Lanba Township of Zhaojue County, and Mu'er Township of Butuo County, all of which are in Liangshan Prefecture. These clauses relate to ten categories: ownership and inheritance of land property, hierarchical relationships, tenancy relationships, debts, insurance, criminal laws, marriage, administration of justice and chattel. We are unable to demonstrate in detail all these clauses in our film, yet we can focus on the relations between the Yi social structure and customary law, and the interactive relationship between the Customary Law of the Yi people and national laws within the basic framework of legal pluralism. Furthermore, through the visual description of the cases in the film, we can "record the occurrence, development, and settlement of the event, the strategies of the two parties, the mediator, and the mediation strategies, in an attempt to voice the opinions of the two parties involved in the case and that of the third party. By doing so, we can present how these figures' social status, cultural distance, and level of respect come to affect the operation of customary law." (Yang Zhiwei (杨志伟) (n.d.)) The film will achieve what written words cannot by bringing the audience an immersive experience.

\section{"Degu" A'er Yangtie and a "Sigei" case}

In addition to the unique dispute settlement methods under Yi Customary Law, the disputes themselves in many cases are very distinctive, reflecting the unique characteristics of this ethnic group's culture. In this film, we choose to uncover the unique cultural features of the Yi people via the Sigei phenomenon, which has been particularly for other cultures to understand. Sigei is a word invented by academics to refer to the Yi word "Sijibi." Sijibi refers to a sort of "suicide" (Durkheim, 1996:144-298.) that is caused by civil disputes and can lead to serious conflicts between Yi families even entire lineages. Sigei has a directional meaning for the Yi People, that is, to "commit suicide as a protest against one's opponent." In other cultures, what 
determines the outcome of a dispute case are laws, rules, and even the moral and psychological disposition of the public. In the Yi society, however, a party occupies the commanding height in morality and justice over the other by performing Sigei, and further wins the ultimate success in the dispute. The concept of "The dead have the final say" is often difficult for those outside Yi society to understand. In Haninhibited regions, some also use phrase "I'll kill myself in front of you" as a threat to direct mental distress towards the other party, but of course the actual effect would be one-sided. Generally, the phrase is more of an indication towards the actor's own psychology, or a means of self-relief. In mainstream cultural systems, it is hard to transmit such stress to one's opponent. In other words, it is accepted that a suicide in our cognitive system is an action not involving the other party. Any cause for suicide is considered a low-level factor in terms of morality, and cannot change the determination of legal responsibility. Therefore, it would be impossible for the act of suicide to mobilize the relevant resources to deter or penalize the opponent in mainstream cultural systems. However in the folk society of Yi-inhabited regions, cases such as these which would be determined as suicide under state laws, will cause the other party, the one believed to have caused Sigei, to be condemned and even retaliated against by the relatives, friends, and even entire lineage of the deceased. This causes great mental distress for the receiving party, and ultimately they will be punished under the Customary Law of the Yi people. Sigei cases reveal the unique characteristics of the Yi people's conceptual system.

Currently, academic studies on Sigei cases are still mainly confined to fields such as legal science, legal anthropology, and legal practice. There is little research that takes a comprehensive social or cultural perspective. Émile Durkheim (1996) has applied sociological statistical analysis to classify "suicide" into egoistic suicide, altruistic suicide, and anomic suicide, establishing a causal relationship between suicide and social facts from a methodological perspective. However, the Yi People's Sijibi, or Sigei, phenomenon cannot simply be classified as "egoistic suicide" or "altruistic suicide." It cannot be imputed to social upheaval, either. Due to the particular nature of the Yi people's traditional social structure, it cannot even be explained from the sociological perspectives of "face" (self-respect) and the reproduction of power. From a cultural perspective, some believe that Sigei is the residual continuation of the divine judgment folk custom. This custom was based on the "system of divine evidence" wherein suicide proved an individual's innocence. However, this does not explain the process of the individual achieving mutual dignity with the lineage, or the fact that collective identity is recognized beyond blood and kinship relations. Therefore, any observations of Sigei and cases involving Sigei are bound to be related to the nature of Yi society and culture in Liangshan. Sigei therefore acts as the "medium" and "key" to understanding Yi culture.

In his book Sigei, Sigei Cases and Liangshan Society, scholar Zhou Xing (周 星) (1998) extends the discussion of Sigei phenomena to cover topics such as women, relatives by marriage, feuds and religion. Xing's book eventually questions the intrinsic relation between the nature of Yi society in Liangshan and this phenomenon of suicidal behaviour. In this way, the study of customary laws is rooted in society and culture, and as a result, the discussion on customary laws is 
no longer just a summary of phenomena and facts. Instead, there are more possibilities for meaningful theoretical dialogue. The "conspiring" process of collaborating with local informants to create a visual ethnography stimulates both sides to reflect on their original knowledge, and contributes to removing obscurity around the concepts we have long taken for granted. Thus, we found a method and direction for our practice to reveal the holistic cultural relationships at play among the Yi people.

The main shooting location used for The Rules from Ancestors is in Riha Township, Guli District, Zhaojue County, and the major dispute case in the film primarily took place in Yide Village, Riha Township. In the case, Hailai Erzhe from the Hailai Lineage tried to kill himself by poison to protest against Jike Dayi from the Jike Lineage of the same village. The reason was that Hailai Erzhe was irritated by Jike Dayi who introduced his younger sister, Hailai Erguo, to work in the city without his approval. It is taboo for Yi girls to find a job elsewhere when they are engaged - specifically, then a girl has accepted a wedding gift from her fiancé, but they are not yet married. This was a serious insult to the Hailai Lineage because Jike Dayi took the girl away without her parents' approval. As the girl's elder brother, Hailai Erzhe could not swallow the insult and drank the poison outside Jike's house in an attempt to commit suicide. He was soon found, taken to hospital, and his life was saved. This is a case of failed Sigei. In the Customary Law of the Yi people, Sigei is divided into two different kinds of cases: Successful Sigei and Failed Sigei. According to the different ways one can perform Sigei, it can be divided into Sigei through jumping off a cliff (Wadongqiu), Sigei through taking poison (Duzeqiu), Sigei through hanging (Jiqiu), and Sigei through jumping into the river (Yidongqiu). No matter whether the recipients are innocent or not, they would be judged to be the losing party after Sigei takes place. As the Yi proverbs go, "In wrestling, the person on top wins; in homicide cases, the dead wins". Another saying, "The dead has the final say," can be understood as ending one's life in exchange for the "ultimate victory." This represents how the Yi people cherish "face" or self-respect over all else, even their lives. Sigei is usually treated as a homicide case under the Customary Law of the Yi People. They do not have the custom of "a life for a life". Instead, the solution is to award the "defendant" compensation for "human life loss" with the amount of compensation specifically stated in the Customary Law based on the actual situation.

After the Sigei case took place, the Jike family was under tremendous pressure. Both families selected several prestigious elders called Moda (spokesperson of a family) to handle the dispute. After negotiation, they invited A'er Yangtie, a Degu recognized by both parties and also a villager of Yide Village, to mediate this case. A'er Yangtie is a Great Degu in Guli District and a major character in our film. In the film, he also handles a marriage-property dispute. In Liangshan Yi Autonomous Prefecture, in contrast to the state laws, the two parties will not refute a case that is settled under the Jiewei customary law; they will not try to reverse the result. The customary law has its own set of restraint mechanisms, which act as a social control system supported by the strong power of Yi lineages. Individuals cannot survive independently without relying on family-lineage support. They are at once protected by the power of the lineage and also restricted by it. 
In the process of mediating a case, both parties compete to maximize on their own interests, while the Degu always maintains an impartial attitude. This impartiality is based on the customary law and should never mix with a Degu's personal likes and dislikes, which is also a standard used to judge a Degu. The mediation of a dispute is a process wherein the Degu attempts to persuade both parties by using clauses of the customary law. Unlike hearing and trying a case, the final result of a mediation is a recognition of the customary law of Jiewei by both parties, rather than the result of bargaining. The result, after being accepted by both parties, is binding on all individuals concerned. For more serious cases, a ritual is needed to fortify the effects of the mediation result (such as killing a rooster as a witness curse). Why, then, do we find that cases settled under the customary law are all stable and "will not be reversed", while a court's verdict is unable to satisfy both parties? If one party refuses to comply with the judgment, the other party will remain unsatisfied, and they eventually have to turn once again to the customary law to have the case settled. In the film, we can find out whether authority and mandatory force are in the hands of the local society or the government in the Yi society in Liangshan, and learn about how these factors are changing amid the ever evolving wider social environment of today.

The film shows the entire process involved in these cases and their mediation in great detail. Further analysis and interpretation of the cases are left to the audience. What I wish to present in this paper is our main focus and the narration strategies used in the film.

\section{Methodology}

Traditional ethnographic films: Observational filmsThe narrative methods of anthropological film developed alongside the growth of film theory (or they mutually promoted each other). According to the earliest film theories, films are mainly divided into two categories: fiction films (films telling imaginary stories or feature films) and non-fiction films (films telling true stories and documentaries, including TV documentaries on special subjects). Anthropological films belong to the category of non-fiction film (yet the boundaries between the two categories are becoming obscure). Julianne Burton, a documentary director, identifies the four modes through which documentaries seek to recreate the real world. These are the expository, observational, interactive and reflexive modes. Scholar Bill Nichols categorized documentaries into the poetic, expository, observational, participatory, reflexive and performative. These classifications are essentially the same. The early Science Documentaries on Ethnic Minorities in China were mainly expository documentaries, which were produced and maintained by the Institute of Nationality Studies of Chinese Academy of Social Sciences from the 1950s to 1960s. Most of the current anthropological films are observational documentaries. The observational mode is considered the classic and mainstream anthropological film method used to describe a local society. To achieve this, the main approach and principle is to conduct a fieldwork investigation of the society's "Otherness" under the dual concept of Emic-Etic. They are called observational ethnographic films because 
they observe and express the objective world through film. However, observational films and other traditional ethnographic films are questioned because they are good at describing, but incapable of summarizing and analyzing, phenomena. After that, some interactive, reflexive, and introspective ethnographic film methodologies have emerged, though few sophisticated films have been produced from them. These films generally faced the problems of visibility and operability. When it comes to our project, we firstly need to represent specific customary law cases through film footage, then we must consider how to find a proper entry point for analysis. According to our former experience, we will first use the observational film method during fieldwork, and make corresponding adjustments as our fieldwork advances.

In June 2006, we went to visit Liangshan Yi Autonomous Prefecture, Sichuan for the first time. We mainly surveyed Meigu and Zhaojue counties to select our shooting locations. We found that the Traditional Customary Law of the Yi people was common and functioning well in Liangshan and that it would be better to shoot in the least busy season for farming, from October to the following March, or the local winter time, since more cases would take place during this time. However, the harsh climate in alpine regions posed a real challenge to us. Since there were only two team members in our project, Mr. Chen Jingyuan and myself, we had to consider whether our physical tolerance and the cameras could adapt to the local conditions, and the power supply in remote villages was also a big problem. Then we decided to find a village not very far from a county town, which would make it more convenient and possible for us to shoot the film in the relatively long term. However, all our plans changed completely after we met Ebi Jiefang.

Cooperation: from collaboration to self-consciousness

Ebi Jiefang is a section chief of the Culture and Sports Bureau at Zhaojue County Bureau in Liangshan Prefecture. Previously, he had been a teacher at a local middle school, later joining the organization to take charge of cultural relics and other matters. He had a vast impact on how our film took shape. There is an interesting story behind our encounter. We usually visit local intellectuals and people working at local cultural offices to learn about the overall situation before we start fieldwork. Before we started off, some local cultural elites from Meigu and Zhaojue counties were recommended to us. Unfortunately, they were difficult to get close to, possibly because they were too busy, or they were approached too frequently by scholars from other places, or we were simply newcomers in the research circles interested in Yi people. After an initial survey in Meigu County, we went to visit Zhaojue County.

While waiting at the cultural bureau, we noticed a man looking at us. After he felt certain that we had nothing to do but wait there, he came over for a chat. After a while, we got to know that he was very interested in our project. His name was Ebi Jiefang, and later we learned that he was also a well-known local intellectual in Liangshan Prefecture. During our chat, we became deeply aware of his passion for and understanding of Yi culture. In the following days, we communicated extensively with each other. He strongly recommended that we shoot in Guli District of Zhaojue County. According to him, this county was a remote and isolated area, 
rarely visited by outsiders. He taught there, and believed that it was the area where Yi culture was best protected, with the least impact from the outside world. Despite our different attitudes towards the idea of "impact", we wanted to find somewhere with "influence, conflict, and collision," as this would make for better comparison.

We were more than happy when Ebi Jiefang offered to join us, as he is an expert in the study of Yi traditional clothing with an interest in archaeology. More importantly, he is knowledgeable about the Bimo, Jiewei, and other Yi cultural items. We were grateful to have such an ideal partner. Thus we determined our fieldwork sites in Guli District. Ebi Jiefang proved incredibly helpful in many aspects. He served as our guide, interpreter (in both the linguistic and cultural sense), and even instructor. Cooperation is always the intrinsic form of fieldwork for ethnography. Traditionally, cooperative scenes of ethnography exist between the anthropologists and the object of study as "the Other", to describe and illuminate the internal cultural world of "the Other" that both parties are interested in. Yet this common interest was only revealed when the anthropologists came and imposed their study plan on their key informants (Marcus, 2007) From that we could see the difference in power and the unidirectional, utilitarian nature of a cooperative research relationship. When our project proceeded to the post-production stage, we could feel Ebi Jiefang's certain reflective observations on his own culture and customs, which had a certain, consciously or unconscious, effect on our film production process. At the time I thought that films in the future might be both observational and cooperative. Instead of the unidirectional solicited relationship, there might be a more balanced cooperative relationship based on common interest.

Directing the ethnographic filmmaking process: from "complicity" to "sharing"

Like other non-fiction film categories, anthropological film has changed its narrative strategy from expository narration emphasizing the subjective opinions of the author, to observational narration underlining and recording objective facts, then to interactive narration stressing mutual participation, and finally to reflexive narration advocating conscious introspection. People are constantly exploring and experimenting with new narrative and expressive forms, yet we cannot simply conclude that "the newer, the better". Nor can we discard Grierson's expository narration as useless. In fact, it is up to the author to choose their suitable form, which depends on the appeal and preference of the author and the content the author wishes to present. We only began to consider the narrative strategy of our film when we were in the second half of fieldwork. As we understood more, we did not feel that any one form as the ideal one. This was because our final goal was not to tell audiences our opinion on the Customary Law of the Yi People. Instead, we intended to allow our audience to experience Yi culture in Liangshan Prefecture by themselves, while enabling all of us (the filmmakers, the subject, and the audience) to share the same understanding of the culture during the filming practices. Just as Clifford Geertz (1988) put it, "The relationship among the researchers, the researched, and the readers should change, and the researched should not simply be the object of description, and the reader is not simply the person being informed passively. To 
present an ethnography, dialogue among these three entities is necessary." Then how were we to achieve a dialogue? Below we will analyze this from the perspectives of the narrative subject and object, as well as the distance and location of the film.

\section{Subject-object, emic-etic, and distance-location}

Expository narration relates the narrative subject (the photographer/filmmaker) to the object (the photographed/filmed). The filmmaker keeps away from the subject to a certain extent for the purpose of "introduction". This form is characterized by: 1. Omniscience; 2. Instructive voiceover; and 3. Plenty of medium-long scenery shots (left blank for narration). This kind of film are prone to becoming excessively subjective. In this way, the photographer and the photographed are isolated from each other in terms of their location. In such films that feature unidirectional transmission of information, dialogue is out of the question. This narrative strategy is now rarely applied to anthropological films, although it is still widely used in TV documentaries, such as some historical and cultural documentaries, and other specialized TV documentaries.

Observational narration focuses on the narrative subject (the photographed) and the object (the photographer/filmmaker). At present, observational films are the mainstream form of anthropological film in China, since they focus more on the informants, who are featured speaking in a reporter style, and are better aligned with the emic approach to anthropology. However, they pay too much attention to objective observation (such as the Direct Cinema genre in the US). They deliberately keep a distance between the filmmaker and the photographed subject, showing a detached attitude. "The main achievement of observational films is that they once again instruct people on how the camera should frame a shot, yet they fail to create standardized observation attitudes, restricting the director in how they can display emotion. In addition to causing the filmmaker to stagnate and become rigid in their analysis of events, they lead to a numbness and lack of interaction between the observer, the observed, and the audience." (MacDougall, 2001:137).

Interactive narration involved the filmmaker and the photographed cooperating in various ways, during which the emic-etic paradigm is frequently changing, so the distance between the object and subject is clearly narrowed. "In such films, the filmmaker admits that he has entered the world of the subject and invites the subject to get involved in the filming and leave behind their cultural characteristics." (MacDougall, 2001:137) Interactive narration could be taken as a "dialogue-based" form of film expression, although the dialogue exists only between the filmmaker and the subject/photographed. Audiences are still the passive receivers. Reflexive narration is specifically designed to make up for such a defect. In reflexive films, authors would also place their own perspectives under examination, and thus the position of audiences is finally attended to. Such films try to trigger the subjective initiative and self-perception of audiences. However, since these films are often still experimental ones, somewhat restricted and hard to operate, it is still impossible for them to be widely applied. 
"Sometimes the elements of one culture cannot be depicted through another culture's ways of thinking. For this reason, during the production of ethnographic films, the filmmaker must try to allow audiences to have the chance to experience and understand the social experience of the subject." (MacDougall, 2001:134) We also hope that our filmmaking process can achieve this, and produce a piece of research on Yi customary law that avoids the mistake of "making up the legal framework" of the informant group only with knowledge, attainment, and structure developed in a different culture, and then "filling in the materials." (Zhang Guanzi (张冠梓). 2000:57) In our filming practices, the toughest challenges we encountered were on how to use film expression to solve the problems of cross-cultural understanding, information transmission/translation, intervention, participation, reflection, feedback, and applications. In different cultural systems, many translations and interpretations fail to fully understand the culture and value system of "the Other". Therefore, it would be much easier to understand "the Other's" culture if we as viewers could "enter" such a cultural context in some way, allowing us, even if briefly and partially, to better understand each other's culture. In the film The Rules from Ancestors, we try to create "an intermediary context" through Lubi, a unique and powerful belief system and an expressive approach based on proverbs of Yi people. This aims to link the customary law cases with social and cultural reasons, allowing for easier understanding. The main elements of the Rules from Ancestors include: dispute cases - the marriage dispute case and the Sigei case; Degu-A'er Yangtie; two lineages_-Jike and Hailai; the tide of rural-urban migrant workers, as historical context; local opinions-Ebi Jiefang and the film's narrative structure, established in accordance with the explanation of Lubi.

\section{Ebi Jiefang}

Ebi Jiefang served as our guide and interpreter for the project. The cases we witnessed were all found for us by Jiefang through his interpersonal relationships. During observation, Jiefang brought us to the site and worked hard to mitigate the interference we and the camera equipment caused at the event. We realized he was familiar with the local people and had their respect. As a local intellectual, he hoped that we would help to spread, and not misunderstand, his culture. He wanted to learn more about our work and did his best to support us. We communicated a lot. He shared with us the views of the Yi people on specific matters. In return, we let him know our focuses, ideas, and questions. While shooting on location, we were almost always discussing with Ebi Jiefang at the same time.

At the later stage of editing, we needed to process a large quantity of footage, and a big challenge was translating the overlapping dialogue in our recordings. Although we could find Yi translators, we invited Jiefang to work temporarily at our editing room in Beijing, because we believed that Jiefang was irreplaceable for his experience and knowledge and for his efforts in our project. In this way he was actually engaging and taking part in our filming practices. As a local elite from an Yi-inhabited region, Jiefang was not concerned about glamorizing his culture. This is quite different from other cultural stakeholders with enough undue confidence to blindly cater to mainstream discourse out of a sense of cultural responsibility. 
Instead, both on site and while processing footage later on, he took great care to translate the local cultural values as accurately as possible. He had real cultural self-awareness, which became clear after he learned about the purpose of our work. He was able to re-examine things that were familiar to him and add his understanding to his translations. In this way, our cooperative relationship had developed from collaboration, to negotiation, then to complicity. ${ }^{2}$ His translated texts and translation process proved to be an inspiration for the editing and production of our film.

\section{Yi proverbs: Lubi}

The toughest challenge we faced in our post production stage was the translation of Yi proverbs. Ebi Jiefang has spent a lot of time contemplating the suitable Mandarin words to express these sayings. At the very beginning, we could not understand why he would be so particular about proverbs. However, after communicating and interacting with them for a while, we realized that Yi people's modes of expression and thinking are intrinsically proverbial. Lubi, or Yi proverbs, are the distilled essence of language, having been digested during the labor process. They are the refined fragments of life's thoughts, culture, and common sense. Yi people use proverbs much more frequently than other ethnic groups. They play a crucial role in Yi people's lives, with regard to production, daily life, getting along with others, inheritance, development, establishing relationships, and removing injustices. Lubi, which include phrases like mottoes and idioms, constitute the key part of Yi language and an important way of thinking. Evidently, Jiefang feared that if proverbs were not accurately translated, it would result in a quintessential element of his culture being misunderstood. As a matter of fact, Yi proverbs are not just the refined and concentrated results of Yi language, nor mere philosophies on life. They also manifest the entire identity and values of Yi society, carrying with them the history of their traditional culture and even reflecting some authoritative power.

The difference in cultural cognition systems makes it impossible to find an exact match between some proverbs and the words of other languages, and some proverbs can seem strange even in translation. For instance, the following proverbs should demonstrate the acute cultural difference, such as "In wrestling, the person on top wins, yet in a homicide case, the dead wins (摔跤判在上者胜, 命案判死亡 者赢)”, “The rules of cases are binding on the enemy and ourselves, but the rules of debt fall only on our neighbors (案件规矩在敌我, 债务规矩在邻里)”, “People in Han-inhabited regions submit to officials, while people in Yi-inhabited regions submit to Degu (汉地以官为大, 彝区以德古为大)”, “People in Han-inhabited regions believe in written evidence, while people in Yi-inhabited regions look to the

\footnotetext{
${ }^{2}$ George E. Marcus holds, "Against the globalization background, the anthropological ethnography is a cooperative imagination between ethnographers and the local partners with their own awareness of their roles.” See George E. Marcus. 2007. Collaborative Imagination《合作的想象》, Thinking《思想战线》, Issue 4.
} 
testimony (汉地以纸墨为证, 彝区以证言为证)" (all translated by Ebi Jiefang from Yi language to Chinese).

Inspired by this, we considered whether we could incorporate the Yi people's proverb-based way of expressing themselves into the film's structure, just like introducing a new contact or stimulus. Such a structure is what I call the "intermediary context", which connects the emic (the local belief system) and the etic (the belief system of the outsider) within the visual description process. It could change the conventional procedure of viewing a film and interrupt the audience's habitual way of thinking while they watch, by frequently forcing them to revisit the process of trying to understand the proverbs. In this way, audiences should be subconsciously led into the cultural context of the Yi people, and might instinctively attempt to experience and understand the customary law from the native people's perspective. Such "intermediary context" is a form of "complicity" that the author obtained by cooperating and interacting with local people through long-term fieldwork. Under the concept of "complicity", the self-awareness of the observed also becomes part of the filming practice and supports the creation of an "unacquainted" cultural field. Therefore, the Sigei phenomenon and Lubi proverbs are used to achieve the effect of "from being acquainted to being unacquainted (转熟 为生)".

\section{Presentation by sharing: a new way of meaning presentation}

During the production of The Rules from Ancestors, we tried to structurally create an atmosphere that would lead the audience into the Yi cultural context, so as to allow them to understand the Yi people's Customary Law system. The three communication intermediaries we selected were: local Yi intellectual elites, the special proverb system of the Yi people, typical customary law cases.

Two cases were selected to be shown in the film. The first case aims to demonstrate the unrestrained operation of the Customary Law of the Yi people in rural areas, and the second tells about the process of conflict and cooperation between state laws and the customary law. We tried to shift between different narrative contexts. The first half of the film is rendered from our own perspective, introducing various aspects that relate to the Customary Law of the Yi people. In the second part, the Sigei cases are demonstrated in the Yi people's own context. Why would we use the Sigei case instead of other cases within the customary law? The reason is the strong sense of the cultural "Other", the extreme cultural difference that is difficult for the audience to comprehend. Yet it is exactly this great cultural shock that could lead audiences away from their own cultural background to see Yi culture from the Yi people's perspective.

Despite the fact that Ebi Jiefang is not seen in the film, his strong "leading force" can be felt throughout. He paid great attention to the eloquence of the Degu, how the customary rules and clauses were invoked, the strategies that were used, the deterrent forces they produced, and the competition between lineages. This, combined with his outstanding translation of dialogues and subtitles resulted in the film being, to some extent, produced according to his intentions. It is as if our film was directed by him. This was exactly what we hoped to attempt, an ethnographic 
film based on "complicity". Our ethnography thus moved away from cooperation as the traditional central relationship, advancing instead towards a methodological form. ${ }^{3}$

In terms of the film's structure, we did not use a narrative voiceover. In contrast, we divided the 90-min film into ten sections. Before the Sigei cases of the second half, we deliberately added section titles with Yi proverbs relating to the content of each section. This was designed to help the audience make associations between the proverbs and their meaning, thus gradually improving their understanding of each case. These sections include: Section 4: A Sigei Case; Section 5: The Saddle is Good Only If the Horse is Well (马不惊 鞍不坏); Section 6: In Wrestling, the Person on Top Wins, Yet in a Homicide Case, the Dead Wins (摔跤判在上者胜 命案判死亡者赢); Section 7: A Dispute Ending up with Multiple Compensations; Section 8: Jiewei or Laws; Section 9: The Brave are Those Who Dare to Drink until Drunk, and A Successful Case Is One that is Fully Resolved (醉酒躺下为大 案子解决为大). Just as audiences are becoming immersed in the plot of the film, an $\mathrm{Yi}$ proverb that juxtaposes against the preceding context would appear on the screen, interrupting their flow of thought and sparking their curiosity. Being thus forced to try and understand $\mathrm{Yi}$ proverbs would allow them to experience the unique nature of Yi people's Jiewei system. Using this system of proverbs and language, we create the "field" of the "Othered" culture within the film. Without their noticing, we subtly lead the audience into the "field", from which to observe and experience the culture. Nevertheless, what is it that creates the "field" of the "Other" culture? Is it the director, the audience, the local cultural elites, or the subject itself? The answer is all of them. The creation of said field is the result of interaction and cooperation between each of those related actors. Our objective in producing the film is to make such interaction possible. That process is what we call "sharing".

\section{Conclusion}

By creating "an intermediary context" through a visual narrative structure, we have achieved an experimental expression of ethnographic film that progresses from "complicity" to "sharing". We made it possible for the ethnographic film to generate knowledge through a process of cooperation between the filmmakers, the subject, and the audience, thus allowing the film to become a non-unidirectional vector for the flow and transmission of knowledge. As a result of our creative investigation of narrative film techniques, ethnographic films no longer have to be seen as subordinate to the written text. Instead, the film and written text can be viewed equally as the results of knowledge production, achieved through different means.

\footnotetext{
${ }^{3} \mathrm{Fu}$ Xiaoxing (富晓星) put forward the “complicity” status of animation anthropology and we have discussed about the significance of means of "complicity" to visual anthropology.
} 
Acknowledgements 'Not applicable'.

\section{Author's contributions}

The author is the only contributor to this paper. The author read and approved the final manuscript.

\section{Authors' information}

'Not applicable'.

\section{Funding}

There was no specific funding for this paper.

\section{Availability of data and materials}

'Not applicable'.

\section{Ethics approval and consent to participate}

Approved hereby.

\section{Consent for publication}

Given hereby.

\section{Competing interests}

No competing interests.

\section{References}

Chiba, Masaji. 1997. In Legal pluralism [M]. Trans, ed. Qiang Shigong et al. Beijing: China University of Political Science and Law Press.

Durkheim, Émile. 1996. Suicide: A study in Sociology自杀论, 144-P298. Beijing: The Commercial Press.

Geertz, Clifford. 1988. Works and Lives: the Anthropologist as Author. California: Stanford University Press. Hebel, E.Adamson. 1993. The Law of Primitive Man—A Study In Comparative Legal Dynamics初民的法 律, translated by Zhou Yong (周勇), 31-38. Beijing: China Social Sciences Press.

Hu Hongbao (胡鸿保) and Yang Yuzhen (杨玉珍). 2006. Words vs. Pictures-With Special Reference to the Marginality of Visual Anthropology文字VS 图像一兼谈视觉人类学的边缘性. Journal of Guangxi University for Nationalities广西民族学院学报, (Humanities and Social Sciences) (1):91. 
MacDougall, David. 2001. In The movie crossing observational methods 跨越观察法的电影in Principles of Visual Anthropology影视人类学原理, ed. Paul Hockings, 129-P134. Kunming: Yunnan University Press P137, 137.

Marcus, George E. 2007. Collaborative Imagination合作的想象, Kunming. Journal of Ideological Front 4:1-7.

Pospisil, Leopold. 1971. 40 91. Adapted from: Zhang Guanzi张冠梓: theory, method and change of legal anthropology. Social Sciences Abroad 2003: 5.

Yang Zhiwei (杨志伟) (n.d.). Fractured Customary Laws of Yi People in Liangshan《断裂的凉山彝族习惯 法》.Available at: http://www.yizuren.com. Accessed 3 Mar 2012.

Yuasa D., Koike M., and Ohnaka S.: Fundamentals to Legal Anthropology法人类学基础, translated by: Xu Xiaoguang徐晓光, Zhou Xiangqing周相卿, Hong Kong: Huaxia Culture \& Art Publishing House香港 华夏文化艺术出版社. 2001:75.

Zhang Guanzi (张冠梓). 2000. The growth of legal Theories论法的成长, 57. Beijing: Social Sciences Academic Press社科出版社.

Zhang Guanzi (张冠梓). 2003. Legal anthropology: Theories, approaches and evolution,《法人类学的理 论、方法及其流变》, social sciences abroad, 《国外社会科学》, 5 .

Zhou Xing (周星). 1998. In Sigei, Sigei cases and Liangshan society《死给、死给案与凉山社会》in Fieldwork and Culture Consciousness田野工作与文化自觉, ed. Ma Rong (马戎). Beijing: Qunyan Press.

\section{Publisher's Note}

Springer Nature remains neutral with regard to jurisdictional claims in published maps and institutional affiliations. 